\title{
As bibliotecas universitárias em perspectiva histórica: a caminho do desenvolvimento durável
}

\author{
Martha Suzana Cabral Nunes
}

Doutora em Ciência da Informação pelo PPGCI/ UFBA. Professora adjunta do Departamento de Ciência da Informação da UFS.Membro da Rede Mediações e Usos Sociais dos Saberes e da Informação (MUSSI)

Kátia de Carvalho

Doutora em Comunicação/Ciência da Informação pela UFRJ.Pós-doutora em Ciência da Informação pela Université Paul Sabatier, Toulouse III. Professora titular do Instituto de Ciência da Informação/UFBA, e do PPGCI/UFBA

http://dx.doi.org/10.1590/1981-5344/2572

Apresenta a evolução das bibliotecas universitárias como instituições seculares, cuja evolução dá-se a partir do crescimento bibliográfico e do surgimento das primeiras universidades na Idade Média. O objetivo desse artigo é compreender a evolução das bibliotecas universitárias em uma perspectiva histórica de modo a identificar suas características específicas, seus agentes e os dispositivos adotados por essas instituições difusoras do conhecimento. Utilizou-se de pesquisa bibliográfica e documental para elaboração do artigo e discussão do tema. Conhecer esse percurso histórico possibilita a apreensão dos primeiros vestígios das bibliotecas universitárias e sua evolução, seus percalços e desafios, assim como situa a atuação dos profissionais da informação na condução de ações de mediação e apropriação da informação na perspectiva da formação de indivíduos não apenas competentes em informação, mas capazes de exercer seu protagonismo social.

Palavras-chave:

Biblioteca universitária; Biblioteconomia; Profissional da informação. 


\section{University libraries in a historical perspective: on the way to sustainable development}

It shows the evolution of university libraries as secular institutions, which evolution occurs from the bibliographic growth and the emergence of the first universities in the Middle Ages. The objective of this paper is to understand the evolution of university libraries in a historical perspective in order to identify its specific characteristics, its agents and devices adopted by these institutions that promote knowledge. It used bibliographic and documentary research to develop the article and discussion of the topic. Knowing this historical route allows the apprehension of the first traces of university libraries and their evolution, their mishaps and challenges, as well as places the role of information professionals in the conduct of mediation activities and information ownership in connection with the training of individuals not only competent in information, but able to exercise their social role.

Keywords: University library; Librarianship; Professional information.

Recebido em 01.10.2015Aceito em 18.02.2016

\section{Introdução}

As bibliotecas universitárias ocupam lugar de destaque na sociedade atual. Sua abrangência e o papel que desempenham em prol do desenvolvimento científico, tecnológico, cultural e social estão diretamente relacionados à função da universidade na sociedade como agente catalizador e difusor do conhecimento científico advindo das contribuições dos pesquisadores, docentes e discentes.

Sendo espaços de difusão do conhecimento por excelência, as bibliotecas universitárias, assim como todas as demais unidades de informação, têm evoluído com o passar do tempo a fim de atender não apenas às necessidades de informação do público, como também no sentido de acompanhar as mudanças no campo das tecnologias da informação e comunicação, assim como as mudanças de nível comportamental dos usuários, cada vez mais conectados.

Nesse contexto, entender a evolução dessas instituições contribui para aprofundar as discussões em torno do papel das bibliotecas 
universitárias no âmbito das instituições de ensino superior, destacando sua importância, sua evolução e suas contribuições para a formação crítica e ética de indivíduos capazes de exercer com êxito seu protagonismo social.

Dito isso, este artigo tem como objetivo compreender a evolução das bibliotecas universitárias em uma perspectiva histórica de modo a identificar suas características específicas, seus agentes, bem como os dispositivos adotados por essas instituições difusoras do conhecimento.

Para tanto, foi desenvolvida pesquisa descritiva de abordagem qualitativa, cujo fio epistemológico baseia-se na compreensão de que as bibliotecas universitárias têm um papel social de destaque na sociedade contemporânea, e para a qual confluem os interesses da comunidade da qual elas fazem parte. Foi realizada pesquisa bibliográfica e documental.

O artigo divide-se incialmente pela Introdução, seguida de uma seção que apresenta os vestígios das bibliotecas universitárias na Idade Média. Outra seção ocupa-se em apresentar a evolução das bibliotecas universitárias no Brasil, seguida das considerações finais e referências.

\section{Primeiros vestígios das bibliotecas universitárias}

Ao longo da sua história, as bibliotecas foram evoluindo e adaptando-se às mudanças que estabeleceram suas atuais características e seu papel social. Elas estão ligadas historicamente ao desenvolvimento humano e social, e neste sentido também exercem uma importante tarefa para a mediação da informação, acompanhando não apenas a evolução da produção escrita e da circulação do conhecimento, mas também a evolução tecnológica que favorece o processo comunicacional.

Instituições milenares, elas foram definindo seu papel ao longo do tempo, estabelecendo seu espaço e oferecendo serviços ao público de maneira a encontrar-se como polo aglutinador de saberes, mas também como centro de profundas mudanças responsáveis por mantê-la viva e em atividade mesmo com todos os seus desafios.

Assim, chega-se à Idade Média e às corporações de ofícios e às primeiras experiências no sentido da formação das primeiras universidades. Tais corporações são criadas em consonância com a expansão urbana e comercial europeia e têm como foco a associação de profissionais que trabalham num mesmo ofício, abrigados num mesmo regime jurídico, a fim de terem legitimadas suas atividades para fins comerciais. Elas também têm reguladas as relações internas, externas e de aprendizagem que envolvem mestres e aprendizes.

Dentre os tipos de corporações, destacam-se as Universitas studii, que, segundo Veiga (2007, p. 17-18) caracterizam-se como "[...] associação de alunos e mestres para transmissão e aprendizagem de conhecimentos 'desinteressados', ou seja, sem aplicabilidade imediata.". Porém, durante a Idade Média, a Igreja é a instituição que possui o monopólio sobre a educação, definindo assim, métodos, práticas, conteúdos e os espaços para ensino. Essa dualidade entre as recémcriadas corporações e a Igreja culmina com alguns conflitos tendo como 
alvo principal o controle e a administração do ensino nas crescentes cidades ocidentais.

Assim, as Universitas crescem em consonância com o aumento na quantidade de alunos e demandam a autorização por parte da Igreja de criação de escolas fora do seu espaço original, concedendo-se concessões a clérigos e leigos para criar suas escolas. Daí ressaltar em seus estatutos várias de suas regras relacionadas aos procedimentos e profissionais, e às práticas comuns a qualquer associação profissional, como a realização de assembleias, e os rituais de avaliação, que conferem o grau aos concluintes dos cursos. Dessa forma, garantem sua autonomia em relação à Igreja. (VEIGA, 2007)

Veiga (2007) apresenta uma categorização para as universidades criadas nesse período, conforme o modo com o qual foram surgindo. Essa classificação está apresentada no Quadro 1:

Quadro 1 - Tipologia e ano de criação das primeiras universidades na Idade Média

\begin{tabular}{l|l|c}
\hline \multicolumn{1}{c|}{ Tipo de formação } & \multicolumn{1}{c}{ Universidade } & \multicolumn{1}{c}{ Ano de criação } \\
\hline \hline Espontânea & Oxford (Inglaterra) & 1214 \\
& Montepellier (França) & 1220 \\
& Bolonha (Itália) & 1230 \\
& Paris (França) & 1250 \\
\hline Formadas por migração & Pádua (Itália) & 1222 \\
& Cambrigde (Inglaterra) & 1318 \\
\hline Instituídas por autoridades & Nápoles (Itália) & 1224 \\
religiosas ou da nobreza & Salamanca (Espanha) & 1218 \\
& Valladolid (Espanha) & 1250 \\
& Lisboa (Portugal) & 1290 \\
\hline Criadas por decreto real & São Domingos (América Espanhola) & 1538 \\
& Lima (América Espanhola) & 1551 \\
& México (América Espanhola) & 1551 \\
\hline
\end{tabular}

Fonte: VEIGA (2007).

Observa-se, dessa maneira, que boa parte das universidades mais antigas que se tem notícia é criada a partir das Universita studii, mas o aumento no quantitativo de alunos e mestres e a necessidade de atender às demandas por carreiras profissionais, além do fortalecimento dos estados monárquicos, alteram sobremaneira a dinâmica de criação e funcionamento das universidades a partir do Século XIV (VEIGA, 2007).

Agregadas a essas instituições surgem também suas bibliotecas. Mesmo ainda resultando de uma tradição monacal tendo em vista o grande número de bibliotecas vinculadas aos mosteiros e às congregações religiosas, as bibliotecas universitárias atendem diretamente às necessidades de bibliografia descrita nos currículos dos cursos superiores. Essa necessidade por leitura, e leitura impressa, marca também a evolução bibliográfica vista a partir do Século $X V$, superando tradições e barreiras relativas ao objeto livro e a fidelidade de seus conteúdos.

Martins (1996, p. 82) apresenta a seguinte classificação para as bibliotecas da Idade Média, conforme sua entidade mantenedora: 
[...] as bibliotecas monacais (e entre elas incluiremos, não só por afinidade como por suas origens históricas, a Vaticana), as bibliotecas das universidades e as bibliotecas particulares (mesmo as que eram constituídas pelos reis e grandes senhores pertenciam-Ihes a título por assim dizer privado ou pessoal; só mais tarde é que, por força de uma evolução natural, elas se transformaram em bibliotecas 'oficiais' e públicas).

Segundo Martins (1996), considerando-se que as primeiras universidades têm forte influência religiosa das ordens eclesiásticas, é a partir do Século XV que as universidades e suas bibliotecas universitárias começam um processo de laicização, como nas bibliotecas da Universidade de Oxford e de Paris.

Para essas instituições, Martins (1996) destaca duas características importantes: em primeiro lugar a sua criação a partir de doações de coleções particulares, sejam de reis ou nobres ou mesmo de homens letrados, o que aumenta o volume de seus acervos, e em segundo lugar a crescente importância da figura do bibliotecário nessas instituições. Assim ele relata: "[...] É, pois, já nos alhores da Renascença que a biblioteca começa a adquirir o seu sentido moderno, a sua verdadeira natureza, como é também nessa época que surge, junto ao livro, a figura do bibliotecário[...]". (MARTINS, 1996, p. 91)

Martins (1996, p. 91) revela que é no Século XV, em decorrência do aumento das riquezas materiais das universidades, que as bibliotecas universitárias evoluem em termos de estrutura física e também de pessoal:

Encontram-se por toda parte importantes bibliotecas universitárias: Órleans possui uma biblioteca jurídica, Paris uma biblioteca médica; Avignon recebe, com essa finalidade um importante legado; Poitiers constrói um edifício especial; Caen, Angers, empregam bibliotecários, Nantes possui até sub-bibliotecários (clérigos) e encadernadores. Fora da França, bibliotecas universitárias são criadas nessa mesma época; a de Cambridge foi fundada em 1444, a de Oxford quase ao mesmo tempo.

A Universidade de Paris, criada no Século XIII, cuja inscrição Universitatis magistorum et scolarium parisiensium aparece em seu selo, cresce progressivamente com a criação das faculdades, cujo modelo de formação baseia-se no latim, e que tem São Tomás de Aquino como um de seus mestres, responsável pelo pensamento teológico e humanista na Europa da época. É de uma de suas faculdades que surge, em 1253, a chamada La Sorbon, considerada como a Sorbonne medieval. Criada por Robert de Sorbon, de onde origina seu nome e de quem recebe a doação dos primeiros livros para a biblioteca, recebe dotação do Rei Louis para se 
estabelecer na rua Coupe-Guele, a qual se torna, posteriormente, rua da Sorbonne. (SORBONNE, 2015, tradução nossa)

Nos estatutos dessa instituição encontram-se descritos detalhes tais como os referentes ao acesso, permitido somente aos membros da universidade, ou às pessoas "recomendáveis e instruídas", desde que acompanhadas de um funcionário. O acesso é negado às crianças e aos iletrados, e é exigido cuidado no manuseio das obras, de maneira a assegurar um ambiente propício à leitura e à perfeita conservação do acervo. Só entra na biblioteca quem esteja devidamente paramentado com beca e boné. (MARTINS, 1996)

A biblioteca vem, porém, de uma tradição como espaço de guarda dos tesouros de textos clássicos, aos quais poucos têm acesso devido principalmente à pressão das ordens religiosas em considerar os livros como meio de profanação para os "não letrados", e mesmo nas primeiras bibliotecas universitárias, em que pese um esforço por tornar a leitura mais acessível ao corpo de mestres e estudantes, o manuseio e a leitura são ainda pouco facilitados. E essa característica observa-se nas bibliotecas universitárias medievais, cujas regras de leitura e uso desses espaços são minuciosamente observadas e exigidas dos membros das universidades, assim como a disposição das estantes e o acesso dos textos aos estudantes. Segundo Martins (1996), os livros são dispostos em prateleiras e estantes, fixados por correntes longas a tal ponto que possam chegar até os espaços onde os interessados podem sentar-se e fazer sua leitura.

Fischer (2006) também aborda esse período do ponto de vista da leitura, enriquecendo o entendimento sobre o processo de fortalecimento cultural da sociedade baseado na leitura. Neste sentido, um dos aspectos mais importantes para o autor é a forma como o homem lida com a informação escrita, a qual evolui desde o papiro até o códice, até ter acesso às produções em papel.

Segundo Fisher (2006), são poucas as pessoas que têm acesso aos livros, mas este quantitativo cresce a partir do Século $X V$, fortalecido também pela criação de periódicos como o Journal de Savants, em Paris e - Philosophical Transactions em Londres, os quais difundem as experiências, teorias e publicações científicas da época.

A partir de então, uma nova classe começa a se fortalecer no âmbito das bibliotecas universitárias e posteriormente nas bibliotecas públicas: o bibliotecário. Martins (1996) apresenta o bibliotecário em dois momentos fundamentais: como um profissional contratado por instituições particulares logo após o Renascimento e até meados do Século XIX; e a partir do Século XIX quando o Estado passa a reconhecer o bibliotecário como um profissional no contexto da sociedade. Segundo o autor, na primeira fase profissional, o bibliotecário é reconhecido como erudito, só passando a ter uma formação mais específica para atuar nas bibliotecas a partir da segunda fase, já no Século XIX.

A partir desse percurso pelo surgimento das bibliotecas universitárias, apresenta-se na próxima seção uma discussão em torno da evolução dessas instituições, como elas evoluíram na sociedade 
contemporânea e quais os serviços que elas disponibilizam aos usuários nas universidades.

\subsection{A evolução das bibliotecas universitárias a partir da idade média}

As bibliotecas universitárias são instituições de ensino superior e estão voltadas para atender as necessidades de todos os membros da comunidade acadêmica da qual fazem parte, mas num processo dinâmico, onde cada uma de suas atividades não é desenvolvida de maneira estática e mecânica, mas com o intuito de agir interativamente para ampliar o acesso à informação e contribuir para a missão da universidade.

Segundo Otlet (1989), uma biblioteca universitária se destina aos estudantes, aos professores, aos especialistas e aos pesquisadores. Além delas, as bibliotecas científicas se organizam dentro de institutos de pesquisa.

Como dito anteriormente, as bibliotecas universitárias foram sendo criadas à medida que as primeiras universidades surgiam desde os Séculos X a XII, tais como as de Bolonha, Paris e Oxford. Porém, segundo Barbier (2013), elas não fornecem os serviços necessários aos alunos e mestres, que muitas vezes usam as bibliotecas das abadias e das escolas monásticas, como as bibliotecas das ordens dos Dominicanos e dos Franciscanos, a fim de atender suas necessidades.

Se inicialmente destinam-se especialmente ao público letrado, mudam gradativamente suas características para adequar-se às novas demandas, configuradas dentro de um contexto de alterações sociais operadas no âmbito religioso e científico. Quais seriam, então, os movimentos que influenciaram as bibliotecas universitárias a partir do seu surgimento? Como se definiram, ou redefiniram a organização dos acervos e o acesso às coleções nesse contexto?

Essa nova fase para as bibliotecas universitárias a partir do Século XV apresenta-se como um reflexo da corrente humanista que invade a Europa, e que ocorre em paralelo à explosão bibliográfica promovida pela invenção da imprensa feita por Gutenberg em 1453. Assim, o Renascimento, como movimento de oposição ao domínio religioso que fundamenta o conhecimento difundido nas universidades criadas na Europa ao longo de toda a Idade Média fortemente apoiadas pela Igreja Católica, também conhecido como movimento Humanista, pretende, ao se fortalecer, criticar a orientação escolástica que vinha das instituições universitárias, pautando sua atuação na transmissão do conhecimento, como indicado por Burke (2003, p.38):

O movimento humanista associado ao Renascimento foi, pelo menos nas intenções, um movimento menos de inovação do que de ressurgimento, o ressurgimento da tradição clássica. Mas esse movimento foi inovador, e consciente disso, no sentido de se opor a muito do saber convencional dos 'escolásticos', em outras palavras, dos filósofos e teólogos que 
dominavam as universidades da 'Idade Média'. (BURKE, 2003, p. 40).

Segundo Battles (2003), a aproximação com a fase Renascentista marca sobremaneira a biblioteca universitária, visto que os acervos de títulos em códice crescem não apenas quantitativamente, mas também qualitativamente, à medida que crescem também as universidades. Citando o caso da biblioteca de Sorbonne, em Paris, o autor descreve que seus títulos servem aos professores para dar suas aulas, e que ao fim do Século XIII o acervo cresce numericamente devido às doações de bibliotecas particulares por meio de herança, configurando um aumento substancial de sua coleção:

Nas últimas décadas do Século, porém, pequenas e grandes heranças, de 4 até 300 volumes, quase dobraram o número dos livros disponíveis na faculdade. Por volta de 1290, a biblioteca contava 1.017 livros. Essa quase duplicação do acervo exigiu que ele fosse organizado. Em 1290 foi elaborado o primeiro catálogo geral da Sorbonne. (BATTLES, 2003, p. 80-81).

A fim de promover a organização da biblioteca, utiliza-se pela primeira vez na Sorbonne o alfabeto, recurso ainda pouco adotado como método de organização, visto que até então, o pensamento vigente leva mais em consideração a ordem racional, que privilegia os assuntos, a qual deve ser desenvolvida pelos estudiosos em suas obras para que sejam descobertas pelo leitor. Além do alfabeto, outro recurso adotado pelas bibliotecas universitárias como a de Oxford é o sistema arábico de numeração. Tais inovações sofrem inicialmente com a rejeição dos céticos humanistas, mas passam a ser adotadas como suporte ao trabalho dos catalogadores, como os que ocupam o scriptore na biblioteca do Vaticano. (BATTLES, 2003)

Até o Século $X V$, a ordem racional do conhecimento e a ordem do alfabeto, ainda vista como arbitrária, coexistem na organização dos catálogos das bibliotecas. Só em meados do Século XVIII é que o crescimento no quantitativo das coleções fez sucumbir a visão racionalista na organização dos acervos, para prevalecer a noção arbitrária com a criação de catálogos organizados de modo alfabético (BATTLES, 2003).

Naquele momento cresce numericamente a quantidade de livros em circulação, ao passo em que avançam também outros formatos e suportes para a difusão do conhecimento, tais como os pequenos artigos distribuídos em folhetins e nas revistas. A dualidade observada nesse período reflete a expansão do conhecimento científico em contraposição ao pensamento humanista, cuja ênfase recaí sobre a exaltação dos textos clássicos. A partir de então, cresce também o pensamento Iluminista, que 
marca a sociedade da época de maneira a enfatizar o pensamento, o conhecimento e a razão como molas propulsoras da sociedade.

Para as bibliotecas universitárias, essas mudanças na forma de conceber e fazer circular o conhecimento exigem adequações para atender a uma nova perspectiva do ponto de vista da palavra escrita. Num capítulo intitulado "guerra dos livros", Battles (2003) retrata muito bem essa fase, onde boa parte das bibliotecas é palco de disputas que refletem o clima da sociedade europeia da época, de oposição entre o antigo e o moderno.

Um dos exemplos é a Universidade de Harvard e a biblioteca que Ihe deu origem, criada em meados do Século XVII. Inicialmente contando com uma coleção doada por John Harvard, pastor que, ao morrer em 1638, deixa uma biblioteca contendo 260 títulos, com mais ou menos 400 volumes para a recém-criada escola de pregadores em Newtone, EUA. Sua coleção baseada em obras de Teologia reflete o caráter puritano de seu criador e de boa parte das bibliotecas formadas no mundo anglosaxão, assim como na América do Norte. As mudanças que se sucedem na Inglaterra e a influência do pensamento Baconiano alteram gradativamente a configuração das bibliotecas universitárias, que passam a absorver um maior quantitativo de livros das novas ciências, além de produtos de um mercado livreiro efervescente, cuja produção advém de dentro dos muros das próprias universidades. Desse modo, a biblioteca da Universidade de Harvard torna-se a quarta maior biblioteca do mundo, cujo catálogo on-line possuía, em 2003, 10 milhões de exemplares (BATTLES, 2003).

O período que se seguiu é marcado pela Revolução Industrial e o surgimento de uma nova corrente de pensamento baseada no lucro do capital. Essa corrente provoca profundas mudanças políticas, econômicas e sociais a partir do Século XVIII, que também marcam o fim dos governos absolutistas e a efervescência popular nas cidades europeias, como acontece na França a partir de 1789.

Todos os documentos apreendidos pelos revolucionários franceses nos palácios e órgãos públicos são confiscados até quando se organiza todo o acervo bibliográfico e documental que passa, a partir daí, a ser considerado como patrimônio nacional, até ser transferido para a Biblioteca da França.

Por outro lado, a produção em massa de livros promovida não apenas pelo baixo custo do papel, mas também pela mecanização do processo editorial, eleva sobremaneira o quantitativo de livros em circulação. Aliada à uma nova preocupação com a formação do povo e a necessidade de fornecer os meios para que essa formação acontecesse de modo completo, as instituições mais beneficiadas nesse período são as bibliotecas universitárias.

A biblioteca da Universidade de Paris, já como a nova Sorbonne, reabre suas portas em 1770 após a expulsão dos jesuítas em 1763, instalando-se na antiga biblioteca do colégio Louis-le-Grand. Com uma coleção de 20.000 volumes, seus fundos provêm de diferentes origens, tais como da biblioteca pessoal de Jean-Gabriel de Montempuis antigo 
reitor da Universidade de Paris, da biblioteca do colégio dos Jesuítas, atribuída em 1764, dos livros de 28 colégios parisienses que são fechados e ressurgem no prédio do colégio Louis-le-Grand, e dos livros comprados de 1766 a 1770 (BIU, 2006).

Mesmo no período revolucionário, onde suas portas são fechadas para que ela seja transformada em prisão, a biblioteca da Sorbonne enriquece seu acervo com numerosas obras confiscadas e passa a ser chamada biblioteca da Universidade de França em 1808 (BIU, 2006).

Dentre as grandes conquistas para as bibliotecas no fim do Século XIX, destaca-se a criação da classificação decimal criada por Mewil Dewey (CDD). Como bibliotecário no Amherst College, ele preocupa-se com o modo de organização (ou desorganização) dos livros nas estantes, assim como em transformar o serviço da biblioteca de modo mais eficiente. Com isso, ele integra em 1876 as experiências desenvolvidas pelos bibliotecários da época num sistema numérico que:

[...] não se limitava a rotular estantes; eles também repartiam as estantes entre os diversos campos do conhecimento. A simplicidade do sistema de numeração decimal uniu-se, assim, a um esquema capaz de acomodar em compartimentos epistemológicos bastante intuitivos todos os livros - não só os que já haviam sido escritos, como os que viriam a ser. (BATTLES, 2003, p. 141-142).

O sistema de classificação criado por Dewey promove grande impacto na organização de acervos nas bibliotecas americanas, e suas ideias são rapidamente absorvidas por várias delas e debatidas na recémcriada American Library Association (ALA), que tem Dewey como um de seus fundadores (BATTLES, 2003).

Outra importante mudança no universo das bibliotecas é instituída por Shiyali Ramamrita Ranganathan. A sua contribuição à Biblioteconomia não se restringe à sua época. Ao lançar o livro Five Laws of Library Science (1931), e os demais publicados posteriormente, Ranganathan deixa para as gerações futuras o seu legado, considerando que suas leis ainda hoje são estudadas com vistas a encontrar soluções possíveis para os desafios que as bibliotecas enfrentam em pleno Século XXI.

Uma das grandes influências de Ranganathan decorre de sua experiência na School of Librarianship do University College em Londres e do convívio com os professores e pesquisadores de sua época. Um desses professores, Berwick Sayers, foi um dos estudiosos da Biblioteconomia, e, assim como Melwil Dewey, possuía forte influência hegeliana.

Decorrente de sua visão holística, Ranganathan pensa a biblioteca como um todo, cujos elementos constituintes são articulados de maneira dinâmica a fim de promover a ampla difusão do conhecimento, acompanhando a evolução da sociedade. Assim, ele refere-se à biblioteca como um organismo dinâmico, que compreende um grande sistema, e que se encontra em constante mutação para atender às especificidades e evolução da sociedade. A biblioteca "[...] é um instrumento de educação 
universal, que reúne e difunde livremente todos os recursos de ensino e dissemina o conhecimento [...]" (RANGANATHAN, 2009, p. 263).

Essas contribuições são fundamentais para projetar a biblioteca num outro patamar de interesse social. Assim, vê-se uma mudança qualitativa nos serviços e na percepção das bibliotecas perante seu público. Segundo Santos, Gomes e Duarte (2014), a biblioteca pode ser vista como um espaço de interação, próprio para o desenvolvimento intelectual dos membros da comunidade acadêmica na medida em que:

[...] favorece o processo dialógico entre sujeitos, seja em um mesmo momento histórico, com os debates e trocas de informações que podem ocorrer em seus espaços físicos e/ou virtuais, ou ainda em tempos históricos distintos, quando os usuários da informação têm acesso aos conhecimentos registrados. (SANTOS; GOMES; DUARTE, 2014, s/p.).

Nessa perspectiva, as bibliotecas universitárias favorecem a aprendizagem dos estudantes, não apenas oferecendo o conhecimento que está acumulado nos diversos documentos em diferentes suportes os quais ela administra, mas também a partir de ações concretas que visam otimizar o desenvolvimento de estudantes e de equipes de pesquisadores no espaço informacional, através de ações de aprendizagem.

Santos (2012) destaca que as bibliotecas universitárias funcionam mais do que simples espaços de busca de informação, mas em todas as etapas de sua atividade está implícito o objetivo de "[...] favorecer o crescimento social e cognitivo dos sujeitos." Dessa forma, seja através da organização, representação, disseminação e uso da informação, as bibliotecas universitárias facilitam o acesso à informação e contribuem para que os sujeitos que a buscam possam se apropriar dos recursos informacionais que ela gerencia. (SANTOS, 2012)

Assim, percebe-se que as bibliotecas universitárias são instituições tradicionais que rapidamente se espalharam por todo o mundo. No trabalho em questão, dois ambientes foram privilegiados e mereceram uma investigação mais apurada que contemple a evolução das bibliotecas universitárias tanto no Brasil e como na França. Decorrente de questionamentos a respeito da concepção histórico-social das bibliotecas brasileiras e francesas e sua importância para a educação superior, apresenta-se a seguir a trajetória dessas instituições a nível nacional e internacional.

\section{A trajetória da biblioteca universitária no Brasil}

No Brasil, a evolução educacional é marcada pela influência advinda da colonização portuguesa, assim como das correntes pedagógicas que se adaptaram à realidade educacional da sociedade brasileira ao longo do tempo. A legislação educacional, acompanhando essa dinâmica, molda ao longo dos séculos o modelo educacional brasileiro, que hoje oferta cursos em todo o território nacional, seja em nível básico, que compreende o 
ensino infantil, fundamental e médio, ou do ensino superior, englobando a graduação e a pós-graduação.

As bibliotecas começam a ser criadas no Brasil a partir do período colonial nos colégios dos jesuítas. Com efeito, é com a chegada das ordens religiosas dos jesuítas, franciscanos, carmelitas e beneditinos que se inicia no Brasil o que se pode chamar de processo de instrução. A crescente demanda de livros para instrução dos meninos, mas também dos mestres, fez surgir bibliotecas em várias províncias como em Salvador e no Espírito Santo, seguindo-se no Século XVII pelos colégios de Rio de Janeiro, São Paulo, Olinda, Recife, Maranhão e Pará (MORAES, 2006).

As bibliotecas das ordens religiosas instaladas na Bahia, por exemplo, são dotadas de importantes acervos, sendo consideradas, conforme descrito por Reis (2008, p. 51), como verdadeiros "centros culturais":

Entre os conventos, na Bahia destaca-se o Convento de São Bento (1575), Convento do Carmo (1586), Convento das Mercês (1654), Convento de Santa Clara do Desterro (1667), Convento do São Francisco (1686), Convento da Soledade (1735), Convento da Conceição da Lapa (1744), todos com bibliotecas dotadas de acervos importantes.

Segundo Moraes (2006, p. 9), essas bibliotecas não são restritas aos membros dos colégios, mas estão abertas "[...] para qualquer um que fizesse o pedido competente." A intenção era equipará-las aos cursos dos colégios das universidades de Évora e de Coimbra. Por esse motivo, suas livrarias são enriquecidas com títulos que fornecem não apenas o ensino adequado das primeiras letras, mas também a formação filosófica.

As bibliotecas jesuíticas tinham, por conseguinte, acervos de nível universitário, abrangendo os mais variados conhecimentos. Serafim Leite afirma que o setor de história e geografia era importante. Para os estudos latinos (língua e literatura) dispunham de grandes edições e seus comentadores [...]. Gramáticas tinham-nas em abundância. O colégio do Rio de Janeiro arrola 110 tomos de gramáticas de diversos autores e dos comentaristas com os respectivos dicionários. Não há dúvidas que essas bibliotecas continham o essencial para os estudos das humanidades em nível superior. (MORAES, 2006, p. 9-10).

O grande golpe dessas bibliotecas ocorre com a expulsão dos jesuítas em 1759, quando boa parte dos seus acervos acaba abandonada e dilapidada. Aliando-se a esse fato a ausência de prensas no Brasil e o controle na circulação dos livros operado a partir da Reforma Pombalina, não restam muitas bibliotecas, a não ser coleções de intelectuais e de particulares ao longo dos Séculos XVIII e XIX (MORAES, 2006). 
A chegada da família real Portuguesa em 1808 ao Rio de Janeiro marca um período importante: o príncipe D. João VI traz consigo a Biblioteca Real Portuguesa, instalando-a no Rio de Janeiro, cria, assim, a primeira biblioteca real do Brasil, atualmente conhecida como Biblioteca Nacional (BN), assim como as academias de ensino superior, que visam atender às necessidades de pessoas formadas para ocupar os cargos públicos.

$\mathrm{Na}$ Bahia surgem os primeiros cursos isolados de nível superior, a exemplo do curso de "[...] cirurgia, anatomia e obstetrícia integrando o Colégio Médico-Cirúrgico, posteriormente Faculdade de Medicina (1808) e, ainda a cadeira de Economia (1808), o curso de Agricultura (1812), de Química e Desenho Técnico (1817)." (REIS, 2008, p. 54)

Ao longo do Século XX várias outras iniciativas surgiram visando a elevar o nível educacional brasileiro como um dos projetos da Nova República que se instala em 1889. Assim, empreendem-se reformas educacionais que visam aumentar o nível de instrução da população e para isso criam-se as primeiras universidades, a exemplo da Universidade de Manaus em 1909 e da Universidade do Rio de Janeiro em 1920, a qual passa a denominar-se Universidade do Brasil em 1937, e a Universidade da Bahia em 1946, e com elas a criação das bibliotecas universitárias.

Do ponto de vista profissional, a formação de bibliotecários no Brasil tem sua origem na criação do primeiro curso de Biblioteconomia em 1911, vinculado à Biblioteca Nacional, e iniciado em 1915, tendo como parâmetro a formação francesa dos conservadores de patrimonio promovida pela École Nationale de Chartes de Paris (SOUZA, 2009). Essa primeira experiência enfatiza a formação humanística, visto que é composta por quatro disciplinas tais como bibliografía, paleografia e diplomática, iconografia e numismática, e cujos conteúdos técnicos estão inseridos na disciplina de bibliografia. (SOUZA, 2009)

Essa influência francesa e humanística na formação do bibliotecário brasileiro estende-se até meados do Século XX, quando cresce fortemente a irradiação da vertente americana para a formação profissional e para a organização das atividades biblioteconômicas.

A influência americana provém, dentre outros aspectos, da Escola de Biblioteconomia de Chicago e das inovações tecnológicas para os serviços de bibliotecas, como heranças da atuação marcante de Mewil Dewey, grande bibliotecário americano e criador da Classificação Decimal de Dewey (CDD) (ORTEGA, 2004).

Uma maior expansão das bibliotecas universitárias dá-se a partir do final da década de 60 do Século XX quando ocorre também o boom da criação de muitas universidades a partir da junção de faculdades isoladas. Segundo Reis (2008, p. 66):

Desde 1961, vem sendo solicitada a criação de biblioteca central nas universidades, como uma das conclusões do $1^{0}$ Seminário Interamericano sobre Bibliotecas Universitárias, realizado em Illinois, nos Estados Unidos, convocado pelo Council of Higher Education in American Republics (CHEAR), 
pois apresenta as seguintes vantagens: maior economia porque evita duplicação de acervo, racionalização de pessoal, aumento da possibilidade de aquisição e catalogação cooperativa, padronização do acervo, oportunidade de haver acervo completo, com vários assuntos, melhor qualidade dos serviços, e, com essa economia, a possibilidade de melhores instalações.

Elas passam a constituir-se como bibliotecas centrais, e absorvem os acervos das bibliotecas de cada faculdade dispostos num grande prédio, mas ao longo do tempo, nesse processo de desenvolvimento e crescimento, passam igualmente a enfrentar problemas, tais como a falta de estrutura física e administrativa, a falta de profissionais capacitados para desenvolvimento dos processos técnicos, principalmente relativos aos serviços de seleção e referência, dentre outros (MIRANDA, 2006).

Em seu trabalho sobre a situação dos acervos das bibliotecas universitárias brasileiras nos anos 70 e 80, Miranda (1993) descreve a realidade problemática relativa aos acervos dessas unidades pela falta de uma metodologia padronizada de análise, aliada à necessidade de maiores investimentos das instituições em suas bibliotecas. O autor destaca que, com a instalação dos primeiros sistemas de gestão destinados às bibliotecas universitárias, há uma carência de dados relativos a essas unidades, o que motiva estudos e pesquisas, seja por parte de institutos governamentais criados no âmbito do Ministério da Educação como o Programa Nacional de Bibliotecas Universitárias (PNBU) a partir de 1979, seja nos eventos profissionais da área como os Seminários Nacionais de Bibliotecas Universitárias (SNBU).

O alerta feito por Miranda (1993) diz respeito à carência bibliográfica dos acervos das bibliotecas universitárias e à defasagem em relação às bibliotecas de outros países, como as bibliotecas das universidades americanas. Segundo dados publicados pela Folha de São Paulo e apresentados por Miranda (1993), as bibliotecas das Instituições Federais de Ensino Superior (IFES) somam em 1987 um acervo de 6,5 milhões de livros contra, por exemplo, 11 milhões de livros somente na Universidade de Harvard.

Reflexo de uma política voltada para o fortalecimento da pesquisa e pós-graduação, Miranda (1993) destaca a importância do Guia de Bibliotecas Universitárias Brasileiras produzido em 1979 pela assessoria de planejamento bibliotecário da CAPES/MEC para o conhecimento da realidade dessas instituições ao longo do Século XX, mas ressalta que, em que pese ser um dos únicos do seu gênero a retratar a realidade das bibliotecas universitárias nesse período, seus dados apresentam inconsistências decorrentes de interpretações variadas do questionário por parte dos respondentes.

$\mathrm{Na}$ tentativa de oferecer uma metodologia sistematizada de formação e análise de coleções em bibliotecas universitárias, Miranda (1993) destaca a necessidade de se estabelecer categorias de análise em 
relação ao acervo informacional, além de definir critérios padronizados de observação relativos ao quantitativo das coleções, idade dos acervos, idiomas das publicações, modo de organização do acervo e correlação com o universo de usuários.

Além disso, e como resultado dos trabalhos desenvolvidos por uma comissão de especialistas convocada pela Secretaria de Ensino Superior do Ministério da Educação (SESU/MEC) para discutir critérios de distribuição de recursos financeiros para aplicação do Programa BIBLOS, ficam evidentes as dificuldades de levantamento de dados neste setor, que conta, em 1990 com 52 instituições em todo o Brasil, com um total de 6.562.366 volumes, e uma média de 18,26 livros por aluno, onde detectase que 36 delas estão abaixo da média da relação de livros por aluno (MIRANDA, 1993).

Com esses dados, Miranda (1993) conclui que, àquela época, era clara a precariedade dos acervos das bibliotecas das universidades federais brasileiras, mas que a adoção de metodologias para avaliação pode melhor subsidiar as decisões dos gestores quanto às políticas de desenvolvimento de acervos e coleções, a fim de serem importantes instrumentos orientadores para as futuras aquisições nessas instituições.

Ao fim do Século XX, a promulgação da Lei de Diretrizes e Bases da Educação Nacional (LDB), em seu capítulo IV, ao tratar dos objetivos, modalidades e critérios relativos ao ensino superior, destaca que ele deve "[...] encorajar o trabalho de pesquisa e investigação científica visando ao desenvolvimento da ciência e da tecnologia e a criação e difusão da cultura, e assim desenvolver uma compreensão de homem e do meio onde ele vive" (BRASIL. Presidência da República, 1996). Para atender esse objetivo, dentre outros, os estabelecimentos de ensino superior, públicos e privados, devem organizar suas bibliotecas, mantendo-as à disposição da comunidade acadêmica, e por isso, a contribuição da biblioteca para a missão da universidade coloca-se em ordem de relação direta. Assim, observa-se que as bibliotecas universitárias têm um papel importante na difusão do conhecimento, na ampliação do acesso à informação e no apoio à promoção do ensino e da pesquisa.

Conforme Anzolim e Serman (2006, p. 7), a biblioteca universitária é um órgão que atua em instituições de ensino superior com a finalidade de oferecer "[...] suporte informacional, complementando as atividades curriculares dos cursos, oferecendo recursos para facilitar a pesquisa científica."

Traçando um cenário das bibliotecas universitárias brasileiras, Russo (2003) também alerta para a necessidade de investimentos voltados à modernização e ao aparelhamento das bibliotecas universitárias, tendo sido esse um campo de discussões recorrentes nas esferas institucionais, como também nos Seminários Nacionais de Bibliotecas Universitárias criados a partir de 1978 .

O Sistema Nacional de Bibliotecas Públicas (SNBP), criado pelo Decreto Presidencial n. 520 de 13 de maio de 1992 como um órgão subordinado diretamente à Fundação Biblioteca Nacional (FBN), define a biblioteca universitária como uma instituição ligada a uma unidade de 
ensino superior, seja pública ou privada, com o objetivo de "[...] apoiar as atividades de ensino, pesquisa e extensão por meio de seu acervo e dos seus serviços. Atende alunos, professores, pesquisadores e a comunidade acadêmica em geral." (SNBP, s/d)

A Comissão Brasileira de Bibliotecas Universitárias (CBBU) é criada no Brasil com a finalidade, dentre outras, de organizar um banco de dados com informações relativas às bibliotecas universitárias brasileiras. Criada em 1987 durante a realização do V Seminário Nacional de Bibliotecas Universitárias (SNBU), após algumas tentativas institucionais de criação de organismos exclusivamente voltados para o debate a respeito da biblioteca universitária, tais como o Programa Nacional de Bibliotecas Universitárias (PNBU), em 1986, e o Programa Nacional de Bibliotecas de Instituições de Ensino Superior (PROBIB), ambos extintos em 1995 (RUSSO, 2003).

A CBBU, vinculada à Federação Brasileira de Bibliotecários, Cientistas da Informação e Instituições (FEBAB), possui como missão "[...] a elaboração de diagnósticos da situação das bibliotecas universitárias brasileiras, com a finalidade de mapear suas características e disponibilidades visando à intensificação de intercâmbio e de programas cooperativos entre elas." (RUSSO, 2003, s/p). Para tanto, a CBBU organiza uma base de dados denominada BIBES, a qual disponibiliza atualmente uma relação de 606 bibliotecas universitárias, desde bibliotecas centrais ou setoriais de instituições de ensino federais e estaduais, além dos institutos federais de tecnologia.

Russo (2003) conclui que a problemática dos investimentos ainda é um fator que assombra as bibliotecas universitárias, e que um novo formato para elas é desejado, revelando necessidades de investimentos não apenas no campo tecnológico, mas também na estrutura física, formação de acervos, produtos e serviços e, em especial, na capacitação de pessoal, a fim de que a biblioteca universitária esteja preparada para enfrentar os desafios do Século XXI.

As bibliotecas universitárias no Brasil são organizadas e dirigidas por bibliotecários, bacharéis em Biblioteconomia formados em instituições de ensino superior brasileiras, conforme a Lei no 9.674, de 25 de junho de 1998 (BRASIL. Presidência da República, 1998), e seu acervo é construído visando atender às demandas de informação para produção de conhecimento pelos diferentes agentes, sejam professores, pesquisadores, alunos da graduação ou da pós-graduação.

Influenciadas pelo advento da internet na década de 90 do Século $X X$ e a inserção das tecnologias de informação e comunicação nas universidades e na sociedade de uma maneira geral, as bibliotecas universitárias buscam também sua modernização, e as experiências passam a priorizar o uso dessas tecnologias no gerenciamento das bibliotecas e na elaboração e disponibilização de catálogos on-line, motivados pelas diretrizes lançadas pela The International Federation of Library Associations and Institutions (IFLA) no fim do Século XX. 
Por essa razão, boa parte das bibliotecas adota sistemas informatizados, a exemplo do Pergamum, o qual é baseado na filosofia dos catálogos online de acesso público (OPAC), visando facilitar a atividade bibliotecária como um todo, e o acesso à informação por parte dos usuários.

Cada biblioteca universitária, seja pública ou privada, organiza-se usando como parâmetro os critérios de avaliação institucional definidos pelo Sistema Nacional de Educação Superior (SINAES) criado pela Lei $\mathrm{n}^{\circ}$ 10.861, de 14 de abril de 2004 (BRASIL. Presidência da República, 2004). Trata-se de um sistema responsável pela avaliação das instituições, cursos e estudantes do ensino superior, considerando os aspectos que giram em torno de eixos principais, tais como o ensino, a pesquisa, a extensão, a responsabilidade social, o desempenho dos alunos, a gestão da instituição, o corpo docente, as instalações. Ele avalia as bibliotecas universitárias, onde são observados critérios como recursos humanos, política de coleções, estrutura física, recursos de informação e comunicação, serviços aos usuários, dentre outros aspectos.

Cunha (2000), um dos pesquisadores que tem se dedicado ao estudo das bibliotecas universitárias brasileiras, traça na virada do Século $\mathrm{XX}$ os principais desafios para essas instituições, prevendo seu futuro em 2010. Segundo o autor, as mudanças nas bibliotecas universitárias estão diretamente ligadas às alterações nas universidades brasileiras, com suas implicações a respeito dos perfis de estudantes e docentes, da produção científica e do uso da tecnologia no âmbito universitário. Dentre os cenários traçados por Cunha (2000) para as bibliotecas universitárias, o autor prevê uma mudança de foco nessas instituições, antes centrado no professor, e agora centrado no aprendiz. Essa mudança tem implicações, por exemplo, na redistribuição do pessoal da biblioteca, com um maior quantitativo voltado para o atendimento ao usuário, na terceirização de serviços e na oferta cada vez maior de serviços educacionais à distância.

Prevendo um ápice da automatização das bibliotecas universitárias, Cunha (2000) apresenta um gráfico da evolução das bibliotecas universitárias, demonstrando sua evolução desde o Século XIX, e identificando quatro eras no processo de evolução tecnológica das bibliotecas universitárias (Figura 1 ): 
Figura 1 - Evolução tecnológica da biblioteca universitária

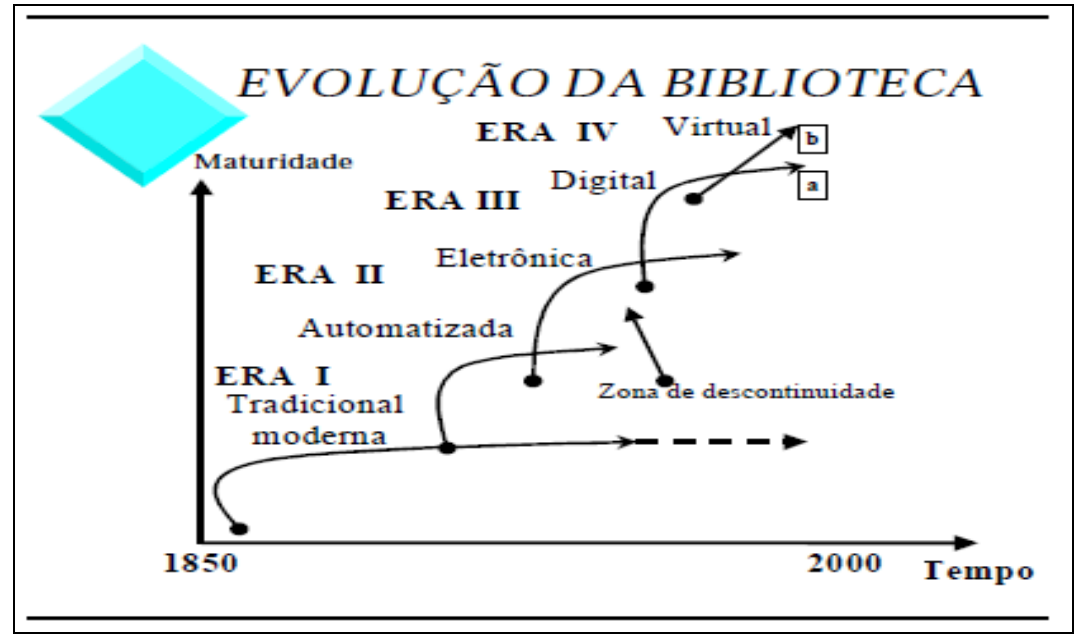

Fonte: CUNHA (2000, p. 77).

Segundo Cunha (2000), e conforme apresentado na Figura 1, a Biblioteca Universitária (BU) transpôs o paradigma da biblioteca tradicional, com localização física definida e o uso de fichas para composição dos catálogos, para o paradigma da biblioteca digital, onde são priorizados "[...] os mecanismos eletrônicos que facilitam a localização da demanda informacional, interligando recursos e usuários." (CUNHA, 2000 , p. 78), e cuja utilização projeta a biblioteca ao nível de cooperação e visibilidade mundial, facilitando o acesso à informação pelos usuários e a formação de redes de informação.

Outrossim, discute-se não apenas o aspecto quantitativo, mas o papel social do bibliotecário na sociedade da informação, assim como as competências que ele deve desenvolver para trabalhar eficazmente com os usuários no âmbito das bibliotecas universitárias. Trata-se, conforme Carvalho (2002), de um profissional diferenciado, cuja formação exige um perfil adequado à transformação no mundo do trabalho e às exigências de mercado, que alteram sobremaneira a caracterização desse profissional, em especial com a difusão das tecnologias da informação.

Observa-se que ainda são muitos os desafios que as bibliotecas universitárias vivenciam, considerando-se que as discussões desenvolvidas nas esferas acadêmica e profissional nem sempre encontram eco junto aos poderes públicos, tanto em relação aos investimentos como à continuidade de políticas públicas que deem maior suporte às ações educacionais e de mediação nas bibliotecas universitárias.

\section{Considerações finais}

Se os fatores ambientais são decisivos para a evolução e configuração das instituições sociais, eles também são responsáveis pela evolução das bibliotecas universitárias ao longo do tempo. Por isso essas unidades de informação tiveram que acompanhar uma série de mudanças a fim de atender aos interesses de seus usuários, e ainda continuam a 
contribuir para que a universidade forme profissionais conscientes de seu papel na sociedade.

A atuação das bibliotecas universitárias, dentro da perspectiva global, envolve a difusão do conhecimento com a aplicação de recursos humanos e materiais na perspectiva da criação de redes de informação, da formação de competências em informação, e da construção do protagonismo social dos indivíduos. Tudo isso exige que as ações dessas bibliotecas sejam conduzidas por profissionais da informação que tenham consciência do seu papel nesse processo de formação de identidades locais, regionais e globais, e que também desenvolvam, eles mesmos, as competências essenciais para atuar muito mais do que com a tecnologia, no lidar com o outro, contribuindo nas ações de mediação e apropriação da informação.

Essas reflexões reforçam a necessidade de que as autoridades universitárias dediquem uma atenção especial aos investimentos nesses recursos para que as bibliotecas universitárias possam atender às demandas de docentes, discentes e da comunidade para o acesso e uso pleno da informação, além de atenção também à capacitação contínua de pessoal que possa agir em prol da evolução dessas instituições, chamadas para atuarem concretamente como unidades mediadoras da informação, ampliando $o$ acesso à informação pública e contribuindo para o desenvolvimento sustentável.

\section{Referências}

ANZOLIN, H. H.; SERMANN, L. I. C. Biblioteca universitária na era planetária. In: SEMINÁRIO NACIONAL DE BIBLIOTECAS UNIVERSITÁRIAS, 14, 2006, Salvador. Anais... Salvador: UFBA, 2006. p. 1-14.

BARBIER, F. Histoire des bibliothèques: d'Alexandrie aux bibliothèques virtuelles. Paris: Armand Colin: 2013.

BATTLES, M. A conturbada história das bibliotecas. Trad. João Vergílio Galerani Cuter. São Paulo: Planeta do Brasil, 2003.

BIU. Bibliothèque Interuniversitaire de la Sorbonne. $A$ I'origine: la bibliothèque de la rue Saint-Jacques (1770-1823). Postado em 11 Oct. 2006. Disponível em: <www.bibliotheque.sorbonne.fr/biu>. Acesso em: 9 jan. 2015.

BRASIL. Presidência da República. Lei no 10.861, de 14 abril 2004. Institui - Sistema Nacional de Avaliação da Educação Superior - SINAES e dá outras providências. Diário Oficial da União, Brasília, 2004. Disponível em: $<$ http://www.planalto.gov.br/ccivil 03/ ato2004-

2006/2004/lei/l10.861.htm>. Acesso em: 14 mar. 2014.

BRASIL. Presidência da República. Lei no 9.674 25, de junho 1998. Regulamenta a profissão de bibliotecário e aborda outras questões. Diário Oficial da União, Brasília, 1998. Disponível em: <http://www.planalto.gov.br/ccivil 03/Leis/L9674.htm>. Acesso em: 14 mar. 2014. 
BRASIL. Presidência da República. Lei no 9.394, de 20 dezembro 1996. Lei de Diretrizes e Bases da Educação Nacional. Diário Oficial da União, Brasília, $1996 . \quad$ Disponível em: <http://portal.mec.gov.br/seed/arquivos/pdf/tvescola/leis/lein9394.pdf>. Acesso em: 14 mar. 2014.

BURKE, P. Uma história social do conhecimento: de Gutenberg a Diderot. Trad. Plínio Dentzien. Rio de Janeiro: Jorge Zahar, 2003.

CARVALHO, K. de. O profissional da informação: o humano multifacetado. DataGramaZero, Revista de Ciência da Informação, v. 3, n. 5, out. 2002.

CUNHA, M. B. da. Construindo o futuro: a biblioteca universitária brasileira em 2010. Ci. Inf., Brasília, v. 29, n. 1, p. 71-89, jan./abr. 2000.

FISCHER, S. R. História da leitura. Trad. Claudia Freire. São Paulo: UNESP, 2006.

MARTINS, W. A palavra escrita: história do livro, da imprensa e da biblioteca. 2.ed. São Paulo: Ática, 1996.

MIRANDA, A. L. C. de. Biblioteca universitária no Brasil: reflexões sobre a problemática. $2006 . \quad$ Disponível em: <http://www.antoniomiranda.com.br/ciencia_informacao/BIBLIOTECA_UN IVERSITARIA_.pdf > . Acesso em: 18 abr. 2014.

MIRANDA, A. L. C. de. Acervos de livros das bibliotecas das instituições de ensino superior no Brasil: situação problemática e discussão de metodologia para seu diagnóstico permanente. Ci. Inf., Brasília, v. 22, n. 1, p. 30-40, jan./abr. 1993.

MORAES, R. B. Livros e bibliotecas no Brasil Colonial. 2. ed. Brasília, DF: Briquet de Lemos, 2006.

ORTEGA, C. D. Relações históricas entre Biblioteconomia, Documentação e Ciência da Informação. DataGramaZero, Revista de Ciência da Informação, v. 5, n. 5, out. 2004. Disponível em: $<$ http://www.dgz.org.br/out04/Art_03.htm>. Acesso em: 6 out. 2013.

OTLET, P. Traité de documentation. Le livre sur le livre. 2. ed. Liège: Centre de lecture publique de la communauté française de Belgique, 1989.

RANGANATHAN, S. R. As cinco leis da Biblioteconomia. Tradução de Tarcísio Zandonade. Brasília: Briquet de Lemos, 2009.

REIS, M. B. Biblioteca Universitária e a disseminação da informação. 2008. 260f. Dissertação (Mestrado em Ciência da Informação) - Universidade Federal da Bahia, Salvador, 2008.

RUSSO, M. A biblioteca universitária no cenário brasileiro. 2003. Disponível Am: <http://repositorio.cfb.org.br/bitstream/123456789/387/1/A\%20BIBLIOT ECA\%20UNIVERSIT\%C3\%81RIA\%20NO\%20CEN\%C3\%81RIO\%20BRASIL EIRO.pdf>. Acesso em: 22 abr. 2014. 
SANTOS, R. do R. Espaço virtual e a comunicação com os usuários para a mediação da informação: utilização pelas bibliotecas das universidades federais e estaduais brasileiras. 2012. 248f. Dissertação (Mestrado em Ciência da Informação) - Universidade Federal da Bahia, Instituto de Ciência da Informação, Salvador.

SANTOS, R. do R.o; GOMES, H. F.; DUARTE, E. N. O papel da biblioteca universitária como mediadora da informação para construção de conhecimento coletivo. DataGramaZero, Revista de Informação, v. 15, n. 2, art. 4, abr. 2014. Disponível em: <http://www.dgz.org.br/abr14/F I art.htm>. Acesso em: 18 abr. 2014.

SILVEIRA, Fabrício José Nascimento da. O bibliotecário como agente histórico: do "humanista" ao "moderno profissional da informação". Inf. \& Soc., João Pessoa, v. 18, n. 3, p. 83-94, set./dez.2008.

SISTEMA NACIONAL DE BIBLIOTECAS PÚBLICAS (SNBP). Disponível em: <http://snbp.bn.br/tipos-de-bibliotecas/>. Acesso em: 14 mar. 2014.

SORBONNE. La fondation de la Sorbonne au Moyen Âge par le théologien Robert de Sorbon. Disponível em: <http://www.sorbonne.fr/lasorbonne/histoire-de-la-sorbonne/la-fondation-de-la-sorbonne-au-moyenage-par-le-theologien-robert-de-sorbon/>. Acesso em: 17 jan. 2015.

SOUZA, F. das C. de. O ensino de Biblioteconomia no contexto brasileiro: século XX. Florianópolis: Ed. da UFSC, 2009.

VEIGA, C. G. História da Educação. São Paulo: Ática, 2007. 